\title{
PEMBANGUNAN SISTEM INFORMASI PERPUSTAKAAN SEKOLAH DASAR BERBASIS WEB
}

\author{
Stephanie Pamela Adithama ${ }^{1}$, Martinus Maslim*2 \\ ${ }^{1,2}$ Program Studi Teknik Informatika, Fakultas Teknologi Industri \\ Universitas Atma Jaya Yogyakarta \\ Jl. Babarsari 43, D.I.Yogyakarta 55281, Indonesia \\ *E-mail: martinus.maslim@uajy.ac.id
}

\begin{abstract}
Pangudi Luhur Elementary School is an elementary school in the city of Yogyakarta that has library facilities to support teaching and learning activities. This library still uses conventional methods in its business process activities. The process takes a lot of time and increases the risk of errors in library data management. The manual system currently implemented is no longer sufficient for handling workloads, especially routine activities, such as book procurement, book cataloging, and borrowing books supervision. Such conditions require the use of computer technology-based information systems. One of them is a web-based information system that is applied to the library. This system was developed in the scope of the library including the ability to record library member data, library book data, borrowing and returning transaction data, calculate late fees, and make reports as needed. With this library information system implemented, it can improve the effectiveness and efficiency of time and energy, and facilitate librarians in compiling reports relating to library management.
\end{abstract}

Keywords - information system, library, school, Pangudi Luhur Elementary Schools Yogyakarta

\begin{abstract}
Abstrak
Sekolah Dasar Pangudi Luhur merupakan sekolah dasar di Kota Yogyakarta yang memiliki fasilitas perpustakaan sebagai penunjang kegiatan belajar mengajar. Perpustakaan ini masih menggunakan cara konvensional dalam menjalankan proses bisnisnya. Proses tersebut menyita cukup banyak waktu dan memperbesar risiko kesalahan dalam pengelolaan data perpustakaan. Sistem manual yang saat ini diterapkan tidak lagi memadai untuk penanganan beban kerja, khususnya kegiatan rutin dalam bidang pengadaan buku, katalog buku, dan pengawasan peminjaman. Keadaan demikian menuntut penggunaan sistem informasi berbasis teknologi komputer. Salah satunya adalah sistem informasi berbasis web yang diterapkan pada perpustakaan. Sistem ini dikembangkan dalam lingkup perpustakaan mencakup kemampuan untuk mengelola data anggota perpustakaan, mengelola data buku perpustakaan, mencatat transaksi peminjaman dan pengembalian buku, menghitung biaya denda keterlambatan, dan membuat laporan sesuai dengan kebutuhan. Dengan diimplementasikan sistem informasi perpustakaan ini, dapat meningkatkan efektivitas dan efisiensi waktu dan tenaga, serta mempermudah pustakawan dalam menyusun laporan yang berkaitan dengan pengelolaan perpustakaan.
\end{abstract}

Kata kunci-sistem informasi, perpustakaan, sekolah, SD Pangudi Luhur Yogyakarta

\section{PENDAHULUAN}

Teknologi saat ini berkembang sangat pesat dan mempengaruhi berbagai aspek dalam kehidupan manusia. Teknologi Informasi (TI) memberikan dampak dalam kehidupan sehari-hari [1]. Salah satu perubahan signifikan yang terjadi dalam kehidupan manusia akibat perkembangan teknologi adalah akses informasi yang sangat mudah dan cepat [2]. Ilmu pengetahuan dan teknologi menuntut kita dapat membuka diri terhadap perubahan-perubahan yang terjadi [3]. Dalam rangka kemajuan organisasi di masa depan, organisasi harus mengadopsi pemanfaatan teknologi, yang merupakan syarat wajib supaya mendapatkan keunggulan dalam kinerja [4]. Salah satu contoh penerapan teknologi di dalam sebuah organisasi adalah dalam bidang pendidikan yaitu 
Sekolah Dasar (SD). Teknologi di bidang pendidikan bisa membantu menjadi sarana belajar maupun menjadi sarana penunjang kegiatan administrasi di dalam sebuah sekolah.

Sekolah Dasar (SD) Pangudi Luhur Yogyakarta adalah salah satu sekolah yang akan menerapkan teknologi informasi untuk menunjang kegiatan administrasi bagi siswa siswinya. Salah satu kegiatan yang akan menerapkan teknologi informasi adalah perpustakaan sekolah. Perpustakaan adalah salah satu fasilitas penunjang kegiatan belajar mengajar yang ada di SD Pangudi Luhur Yogyakarta. Saat ini perpustakaan SD Pangudi Luhur Yogyakarta melayani 766 siswanya yang terdiri dari 6 rombongan belajar (kelas 1 - kelas 6) dan memiliki kurang lebih 3000 buku bacaan. Perpustakaan ini masih menggunakan cara konvensional dalam kegiatan proses bisnisnya. Dalam proses administrasinya, SD Pangudi Luhur Yogyakarta menunjuk pengelola perpustakaan untuk menangani pekerjaan terkait pendataan buku, peminjaman buku, pengembalian buku, serta menyusun laporan-laporan bulanan. Proses ini belum dikerjakan secara sistematis menggunakan komputer. Dengan total siswa kurang lebih sekitar 700 siswa, tentu proses tersebut akan menyita banyak waktu dan memperbesar risiko kesalahan dalam pengelolaan data perpustakaan.

Administrasi secara konvensional ini menimbulkan beberapa kesulitan. Salah satunya adalah waktu yang dibutuhkan menjadi lebih lama. Pencatatan secara manual juga sering menimbulkan kesalahan data yang membuat penyusunan laporan menjadi lebih rumit. Dengan berubahnya data siswa tiap tahunnya karena proses akademik, pekerjaan ini menjadi kurang efisien dilakukan secara manual. Laporan yang baik akan membantu melihat kondisi perpustakaan serta ketertarikan siswa terhadap bacaan secara garis besar. Mulai dari proses pendataan buku, pencatatan peminjaman, serta penyusunan laporan harus terjadi dengan baik dan efisien.

Proses bisnis perpustakaan berkembang dengan sangat pesat dan dinamis, sehingga sistem manual yang saat ini diterapkan sudah tidak lagi memadai untuk penanganan beban kerja. Keadaan demikian menuntut penggunaan sistem informasi berbasis teknologi computer [5]. Sistem informasi berbasis komputer merupakan suatu sistem pengolahan data menjadi informasi yang berkualitas dan digunakan sebagai alat bantu dalam pengambilan keputusan, koordinasi dan kendali serta visualisasi dan analisis [6]. Teknologi digital dan proses digital adalah faktor penggerak revolusi yang terjadi di bidang teknologi informasi terutama di lembaga informasi dan perpustakaan [7].

Solusi untuk permasalahan yang dialami oleh perpustakaan SD Pangudi Luhur Yogyakarta ini adalah pembangunan sebuah sistem informasi berbasis web. Beberapa penelitian terdahulu juga membuktikan bahwa sistem informasi perpustakaan dapat diterapkan pada institusi pendidikan. Penerapan sistem informasi perpustakaan pada Sekolah Menengah Pertama (SMP) dapat mempermudah siswa mendapatkan informasi tentang buku yang ada di perpustakaan. Selain itu, laporan semua aktivitas di perpustakaan, serta informasi tentang keberadaan buku mudah ditelusuri [8]. Laporan-laporan yang dihasilkan ini dapat memberikan informasi mengenai pengelolaan manajemen perpustakaan secara efektif dan efisien [9]. Penerapan sistem informasi perpustakaan pada Sekolah Menengah Atas (SMA) juga telah berhasil dilakukan. Dengan adanya aplikasi desktop perpustakaan ini dapat membantu pustakawan dalam proses pendataan buku, transaksi peminjaman, dan transaksi pengembalian. Dengan pendataan secara komputerisasi maka dapat menghasilkan laporan-laporan secara akurat [10][11]. Akses perpustakaan dapat diperluas dengan penyediaan informasi melalui internet, sehingga dibangun sistem informasi perpustakaan yang dapat diterapkan pada sekolah tinggi. Dengan dibangunnya sistem informasi perpustakaan ini, dapat mempermudah dan mempercepat petugas perpustakaan dalam melakukan pelayanan atau transaksi peminjaman pada perpustakaan [12].

Sebuah sistem yang dikembangkan dalam lingkup perpustakaan mencakup kemampuan untuk mencatat data anggota perpustakaan, mencatat data buku perpustakaan, mencatat transaksi peminjaman dan pengembalian buku, menghitung biaya denda keterlambatan, dan membuat laporan sesuai dengan kebutuhan. Dengan dibangunnya sistem informasi perpustakaan, segala proses bisnis di perpustakaan SD Pangudi Luhur Yogyakarta yang selama ini dilakukan secara konvensional dapat diubah menggunakan komputer. Sistem informasi ini digunakan sebagai alat bantu untuk mengelola seluruh aktivitas yang berhubungan dengan perpustakaan. Selain dapat meningkatkan efektivitas dan efisiensi waktu dan tenaga, serta mempermudah pustakawan dalam menyusun laporan-laporan yang berkaitan dengan pengelolaan perpustakaan. Dengan adanya 
proses pelaporan menggunakan komputer, laporan yang dihasilkan dapat digunakan sebagai acuan dalam proses pengambilan keputusan yang lebih baik untuk mengelola perpustakaan SD Pangudi Luhur Yogyakarta.

\section{METODE}

Sistem informasi perpustakaan yang menjadi topik pengabdian ini dibangun dengan metode pembangunan perangkat lunak yaitu waterfall. Metode waterfall meliputi sejumlah aktivitas sebagai berikut:

\subsection{Analisis Kebutuhan}

Tahapan ini bertujuan untuk mendapat informasi yang mencukupi untuk mengenal latar belakang SD Pangudi Luhur Yogyakarta, proses bisnis perpustakaan, jumlah siswa, jumlah buku bacaan serta permasalahan yang muncul dari proses bisnis perpustakaan saat ini. Analisis kebutuhan ini dilakukan dengan mendatangi langsung lokasi SD Pangudi Luhur Yogyakarta dan melakukan wawancara, khususnya dengan kepala sekolah dan pengelola perpustakaan. Informasi yang akan digali terkait dengan data yang diperlukan untuk pembangunan sistem ini diantaranya adalah data siswa, data buku, tata letak penempatan buku-buku, serta format laporan-laporan yang perlu dibuat.

\section{2 Perancangan Sistem}

Perancangan dilakukan untuk menghasilkan rancangan yang siap diubah dalam kode program. Perancangan dilakukan untuk empat hal yaitu: perancangan arsitektur, perancangan data, perancangan antarmuka, dan perancangan kelas. Beberapa pertimbangan dalam perancangan data adalah efisiensi penggunaan ruang penyimpanan serta penyusunan struktur tabel yang berpengaruh pada kecepatan dalam pembuatan laporan. Arsitektur yang dipilih adalah aplikasi web yang menggunakan REST API sebagai pusat dari transfer data. Arsitektur ini akan memisahkan proses bisnis menjadi dua bagian, yakni bagian back-end (proses-proses yang terkait dengan penyimpanan dan pemuatan data) dan front-end (proses-proses yang terkait dengan sesuatu yang melibatkan presentasi data dalam bentuk yang lebih mudah dipahami oleh pengguna).

\section{3 Pengkodean Sistem}

Pengkodean dilakukan untuk mengubah hasil rancangan ke dalam kode program. Sistem akan dibangun menggunakan bahasa pemrograman PHP, untuk back-end menggunakan framework Laravel, dan untuk front-end menggunakan Vue.js, dan data-datanya disimpan dengan basis data MariaDB. Kode sumber ini akan disimpan pada suatu repositori. Repositori akan memastikan kode sumber selalu konsisten di setiap komputer, baik komputer anggota tim pengembang maupun komputer server nantinya.

\section{4 Pengujian Sistem}

Pengujian dilakukan untuk memastikan setiap komponen sistem berjalan dengan baik. Selama proses pengembangan sistem ini berjalan, akan dilakukan pengujian internal (dalam tim) serta presentasi ke SD Pangudi Luhur Yogyakarta untuk memastikan semua fungsi yang diperlukan sudah sesuai. Pengujian yang akan dilakukan dimulai dari menguji fungsionalitas yang ada pada sistem dengan berbagai data, baik data yang valid maupun yang tidak valid. Dengan pengujian seperti ini, pengembang dapat mengetahui kemampuan dan performa sistem, serta umpan balik dari sistem apabila pengguna nantinya memasukkan data yang tidak valid. Pengembang dapat menyiapkan proses penanganan dengan baik dengan melihat hasil pengujianpengujian tersebut.

\section{5 Pelatihan dan Penyebaran Sistem}

Pada tahap ini kode program yang sudah dibangun akan diunggah ke server agar dapat diakses secara publik melalui internet. Tahap ini dimulai dari proses konfigurasi server. Setelah server dikonfigurasi, dilanjutkan dengan proses pengunggahan kode sumber. Kode sumber ini akan langsung diunggah melalui repositori penyimpanan. Setelah kode sumber diunggah, konfigurasi 
basis data dilakukan. Konfigurasi basis data ini meliputi pembuatan tabel-tabel yang ditentukan dalam tahap perancangan sistem sebelumnya beserta pengisian data-data awal yang diperlukan untuk menjalankan sistem. Setelah dilakukan proses instalasi, maka pengguna-pengguna sistem diberikan pelatihan. Pelatihan ini ditujukan agar pihak SD Pangudi Luhur Yogyakarta dapat secara mandiri menjalankan sistem yang dibangun.

\section{HASIL DAN PEMBAHASAN}

\subsection{Arsitektur Perangkat Lunak}

Arsitektur yang dipilih adalah aplikasi web yang menggunakan REST API sebagai pusat dari transfer data. Arsitektur ini akan memisahkan proses bisnis menjadi dua bagian, yakni bagian back-end (proses-proses yang terkait dengan penyimpanan dan pemuatan data) dan front-end (proses-proses yang terkait dengan sesuatu yang melibatkan presentasi data dalam bentuk yang lebih mudah dipahami oleh pengguna). Dengan arsitektur sedemikian rupa, aplikasi web akan menjadi lebih ramah pengguna. Proses pemuatan data akan dilakukan secara asinkron sehingga mengurangi waktu tunggu pemuatan halaman. Kuota yang diperlukan untuk memuat data akan menjadi lebih hemat karena proses pemuatan halaman web akan menjadi lebih minim.

Pada sisi back-end, komponen-komponen yang akan dikodekan berupa kelas data model, kelas controller, serta pemetaan alamat URL ke kelas-kelas controller tadi. Sedangkan pada sisi front-end, komponen yang dikodekan berupa halaman HTML, CSS, serta komponen logika seperti HTTP Client, komponen penyimpanan data yang akan menampung data dari REST API secara sementara, serta web component yang akan dikodekan secara modular untuk mempermudah proses integrasi. Dalam arsitektur ini, pengembangan back-end dan front-end dapat dilakukan secara terpisah. Komponen-komponen back-end dapat dibangun lebih dulu tanpa menunggu komponenkomponen front-end. Setelah komponen-komponen back-end lengkap, pengkodean komponenkomponen front-end dapat dimulai.

\subsection{Entity Relationship Diagram}

Data siswa yang perlu disimpan seperti NISN, NIPD, nama, jenis kelamin, tanggal lahir, dan kelas. Data buku, yang perlu disimpan seperti ISBN, judul buku, penerbit, pengarang, tanggal terbit, dan kategori buku. Beberapa pertimbangan dalam perancangan struktur basis data adalah efisiensi penggunaan ruang penyimpanan serta penyusunan struktur tabel yang akan berpengaruh pada kecepatan dalam pembuatan laporan.

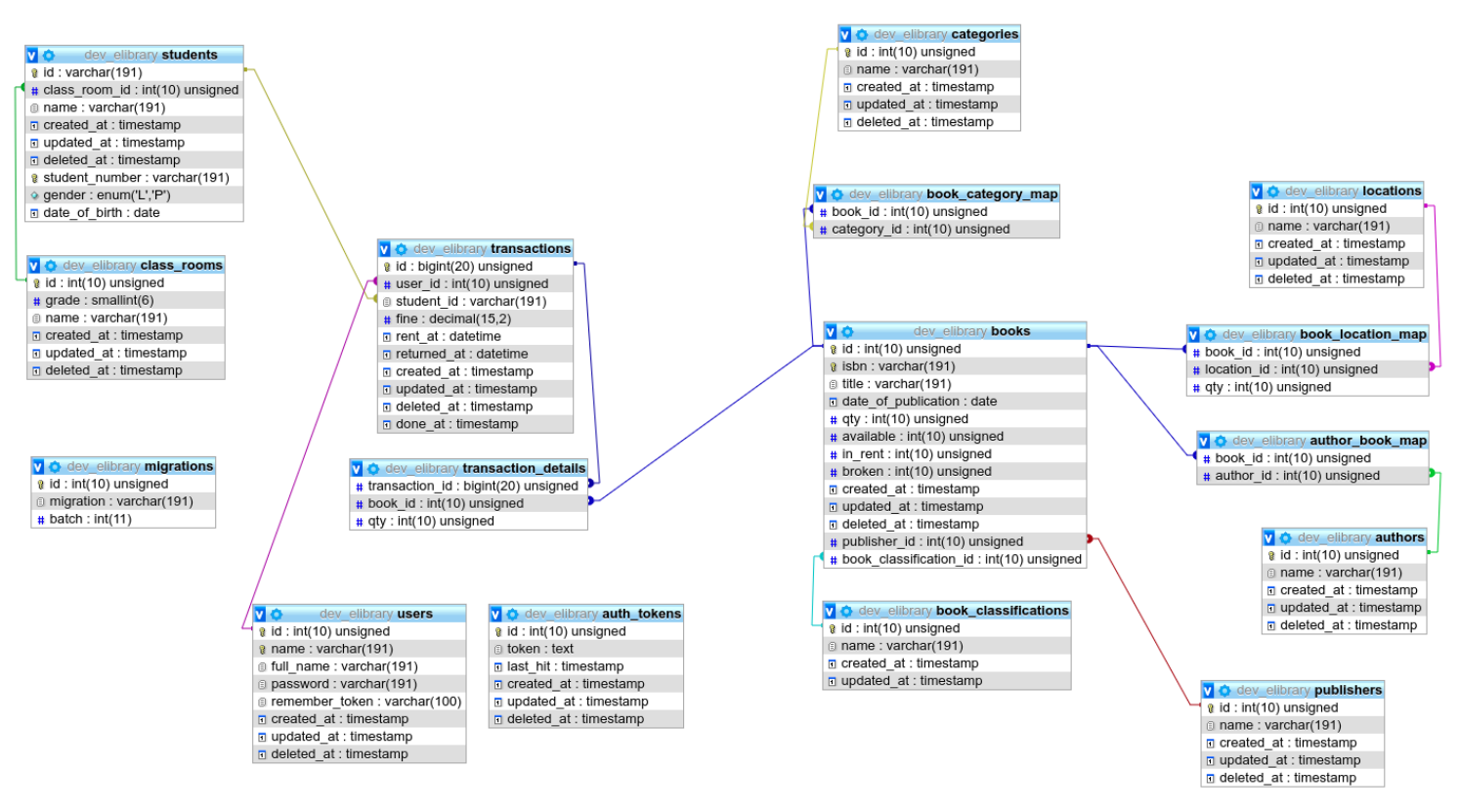

Gambar 1 Entity Relationship Diagram 


\subsection{Implementasi Sistem}

Tahap implementasi ini memiliki arti distribusi akses sistem ke pengguna, yaitu proses pengunggahan kode sumber ke server agar dapat diakses secara publik melalui internet. Tahap ini dimulai dari proses konfigurasi server. Konfigurasi ini meliputi instalasi komponen-komponen perangkat lunak server seperti: Sistem operasi: Ubuntu 16.04, Web server: Nginx, Basis data: MariaDB 10.2, Bahasa pemrograman: PHP 7.2, Kerangka aplikasi back-end: Laravel 5.5, Kerangka aplikasi front-end: Vue.js 2.1.

Setelah server dikonfigurasi, dilanjutkan dengan proses pengunggahan kode sumber. Kode sumber ini akan langsung diunggah melalui repositori penyimpanan kode sumber, hal ini dilakukan untuk menjaga keutuhan kode yang selalu terbarui berdasarkan kode-kode yang telah diuji dan disepakati oleh anggota tim pengembangan. Setelah kode sumber diunggah, konfigurasi basis data dilakukan. Konfigurasi basis data ini meliputi pembuatan tabel-tabel yang ditentukan dalam tahap perancangan sistem sebelumnya beserta pengisian data-data awal yang diperlukan untuk menjalankan sistem.

Setelah berhasil diimplementasikan, maka pengguna yaitu pengelola perpustakaan dapat mengakses fungsionalitas yang ada pada sistem. Pengguna dapat melakukan login, setelah pengguna berhasil login, maka tampilan akan beralih ke halaman dasbor seperti pada Gambar 2 . Pada halaman dasbor ini berisi statistik perpustakaan, persebaran peminjaman, dan persebaran kategori buku. Statistik perpustakaan berisi jumlah transaksi peminjaman, jumlah buku yang dipinjam, serta nominal denda yang dikelompokkan per bulan untuk tahun terkini. Persebaran peminjaman berisi persebaran peminjaman buku yang dikelompokkan per kelas untuk bulan terkini. Persebaran kategori buku berisi persebaran buku yang dikelompokkan per kategori.

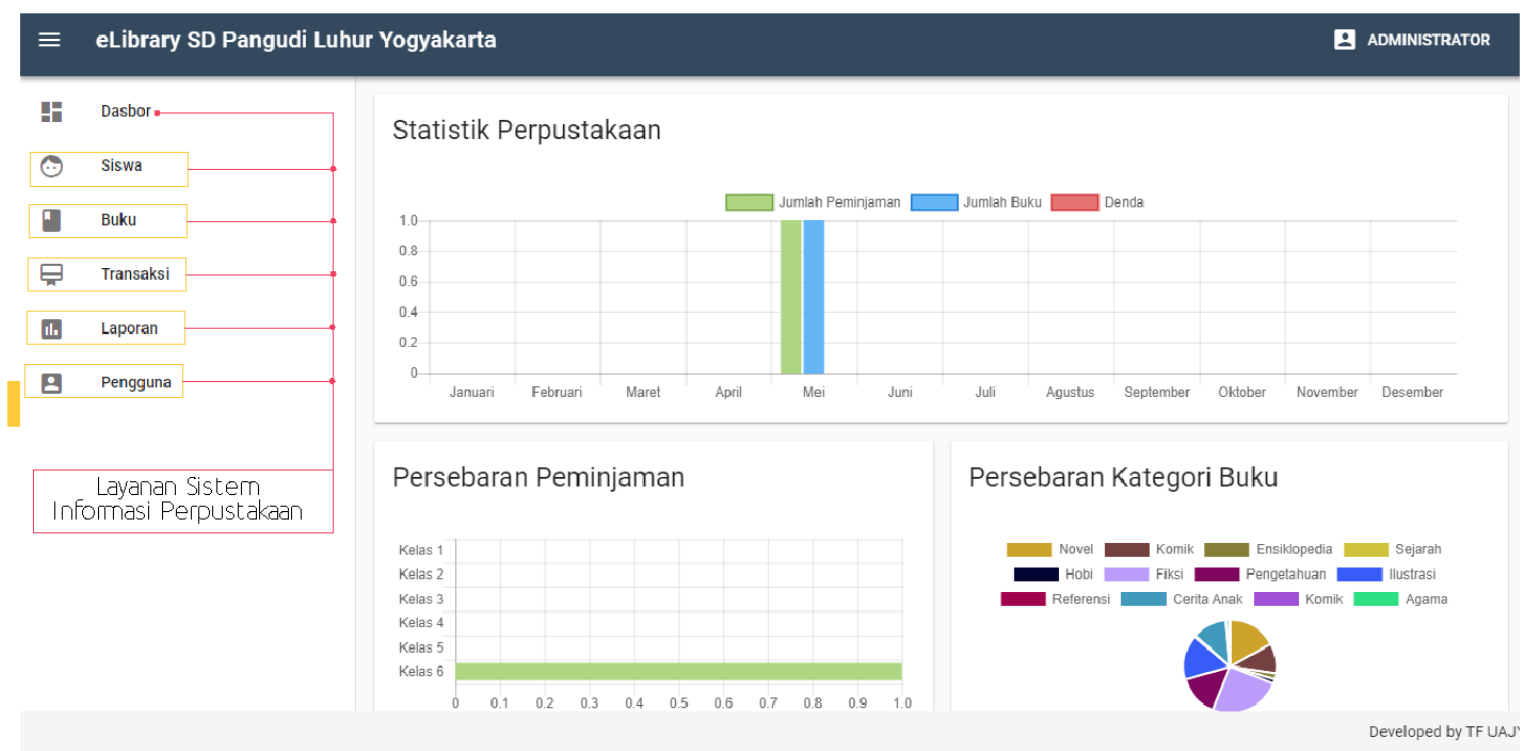

Gambar 2 Antarmuka Dasbor Layanan Sistem Informasi Perpustakaan

Antarmuka pada Gambar 3 memampukan pengguna melihat daftar siswa yang terdaftar dalam sistem perpustakaan ini. Selain itu, pengguna juga dapat melakukan edit data siswa, hapus data siswa, cari data siswa, dan cetak kartu anggota. Pada menu cetak kartu akan dialihkan ke halaman pada Gambar 4, yang berisi data kartu siswa. Pada bagian ini pengguna dapat melakukan cetak kartu. Pada cetak kartu, data yang akan dicetak yaitu: NISN, Nama, Kelas, Barcode. Pada barcode tersebut semua siswa mempunyai barcode yang berbeda-beda, agar saat melakukan transaksi buku, siswa tinggal memberikan kartu peminjaman kepada pengelola perpustakaan agar di scan dengan barcode scanner, agar proses transaksi berjalan dengan cepat. 
DINAMISIA - Jurnal Pengabdian Kepada Masyarakat Vol. 3, No. 2 Desember 2019, Hal. 350-360

\begin{tabular}{|c|c|c|c|c|}
\hline \multicolumn{5}{|c|}{ Daftar Siswa } \\
\hline \multicolumn{5}{|l|}{ Kelas } \\
\hline Kelas 6 - PL1 & & Pencarian & & CETAK KARTU \\
\hline NISN $\uparrow$ & NIPD & Nama & & Tindakan \\
\hline 0041460328 & 3439 & Christian Andhreisco Riahta Sidabutar & EDTT & HAPUS \\
\hline 0041542280 & 3351 & Antonius Bima Putra & EDIT & HAPUS \\
\hline 0042219740 & 2170 & Michele Monica & EDTT & HAPUS \\
\hline 0049770874 & 3440 & Albertus Kefas Yuan Ananda & EDIT & HAPUS \\
\hline 0050673152 & 3364 & Marcelino Rio Mahardika Putra & EDTT & HAPUS \\
\hline 0051027211 & 956 & Aurelia Arimbi Sekar Kinasihing Tyas & EDTT & HAPUS \\
\hline 0051053443 & 2036 & Emmanuel Endy Ismoyo & EDTT & HAPUS \\
\hline
\end{tabular}

Gambar 3 Antarmuka Tampil, Cari, Edit, dan Hapus Data Siswa

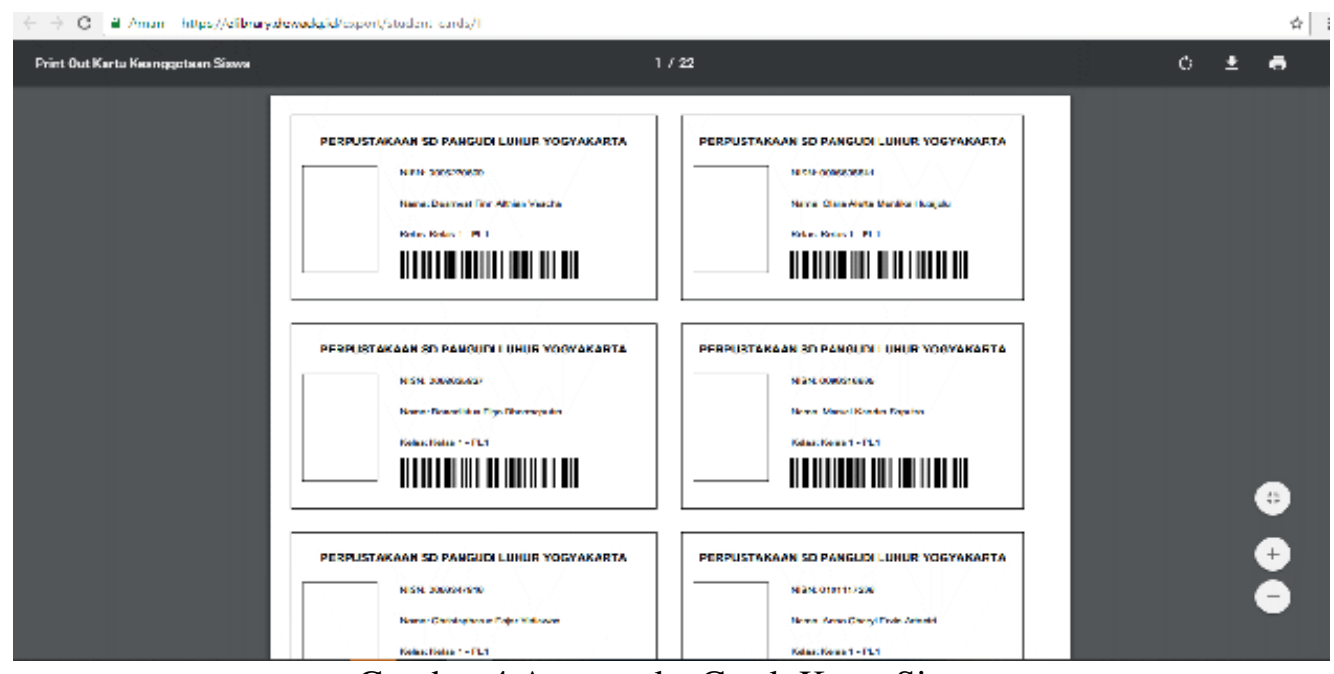

Gambar 4 Antarmuka Cetak Kartu Siswa

Antarmuka pada Gambar 5 merupakan submenu untuk melakukan tambah data siswa, data yang dapat ditambahkan, yaitu : NISN, NIPD, nama, tanggal lahir, jenis kelamin, kelas.

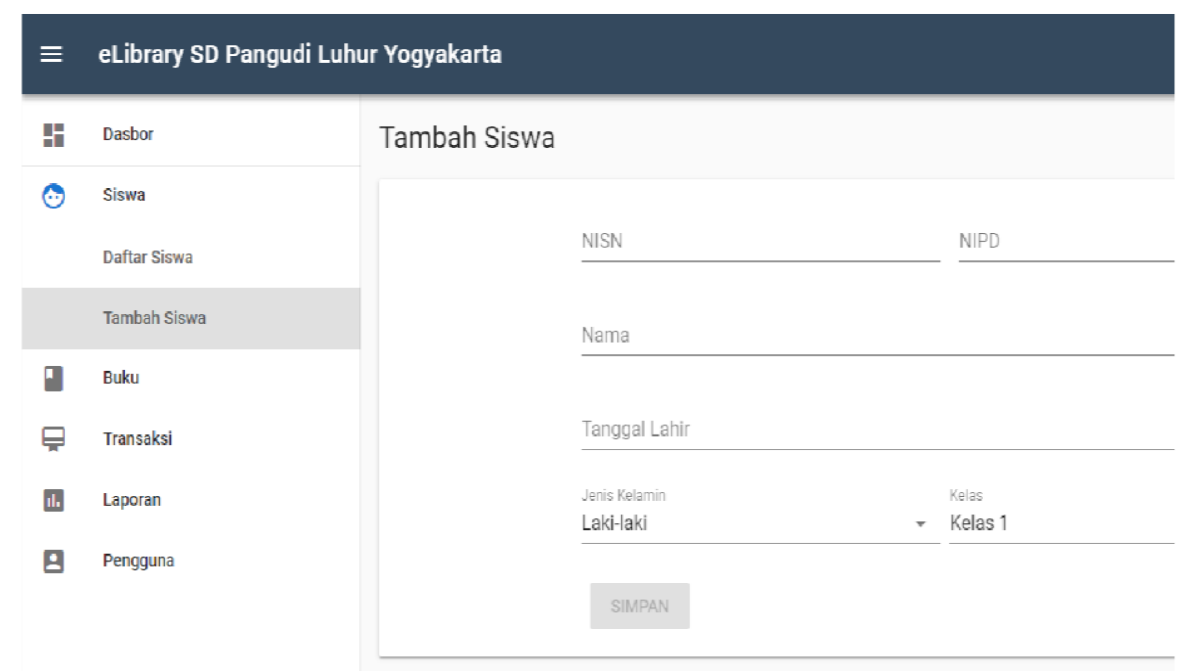




\section{Gambar 5 Antarmuka Tambah Data Siswa}

Menu pengelolaan data buku, memiliki beberapa sub menu diantaranya adalah: pengelolaan data buku, pengelolaan kategori, pengelolaan data pengarang, dan pengelolaan data penerbit. Antarmuka pada Gambar 6 memampukan pengguna melihat daftar buku yang terdaftar. Selain itu, pengguna juga dapat melakukan edit data buku, hapus data buku, dan cari data buku. Pencarian dapat dilakukan berdasarkan ISBN, judul buku, pengarang, penerbit.

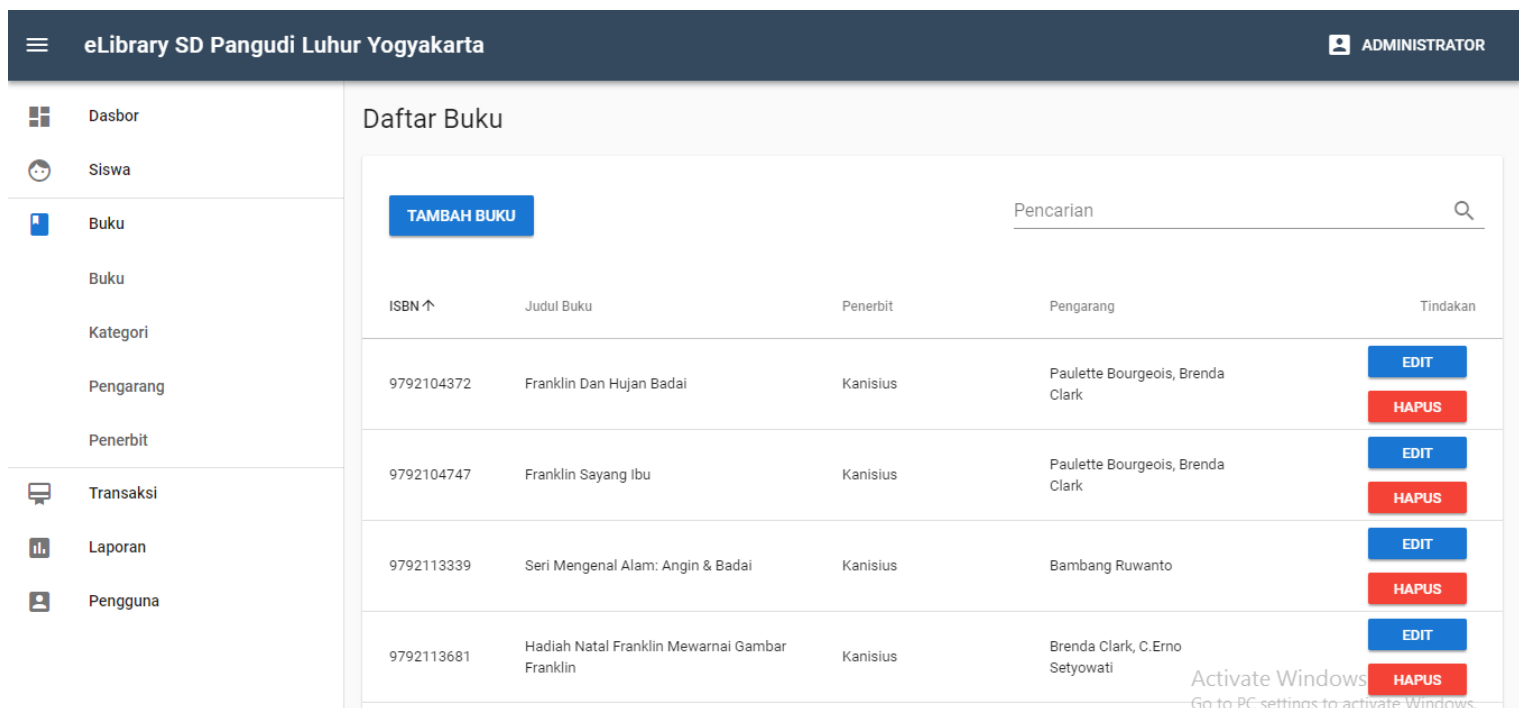

Gambar 6 Antarmuka Tampil, Cari, dan Hapus Data Buku

Antarmuka pada Gambar 7 merupakan menu untuk melakukan tambah data buku dan data yang dapat ditambahkan yaitu: ISBN, judul buku, tanggal terbit, jumlah, tersedia, sedang dipinjam, rusak, pengarang, penerbit, kategori buku. Bila belum ada nama pengarang, penerbit, dan kategori yang ada dalam pilihan, dapat ditambahkan sendiri dengan tombol tambah pengarang, tombol tambah penerbit, dan tombol tambah kategori. Untuk melengkapi data buku, pengguna juga mampu melakukan pengelolaan data pengarang, data penerbit, dan data kategori buku. Untuk pengelolaan ini, pengguna dapat melakukan tambah data, tampil data, edit data, hapus data, dan cari data.



Gambar 7 Antarmuka Tambah Data Buku 
Antarmuka pada Gambar 8, merupakan menu untuk melihat daftar transaksi peminjaman. Data yang bisa dilihat adalah kode transaksi, nama siswa, jumlah buku yang dipinjam, rentang tanggal peminjaman buku, status selesai atau terlambat. Terdapat pula tombol tindakan yaitu tombol untuk melihat detail peminjaman dan tombol untuk menghapus transaksi.

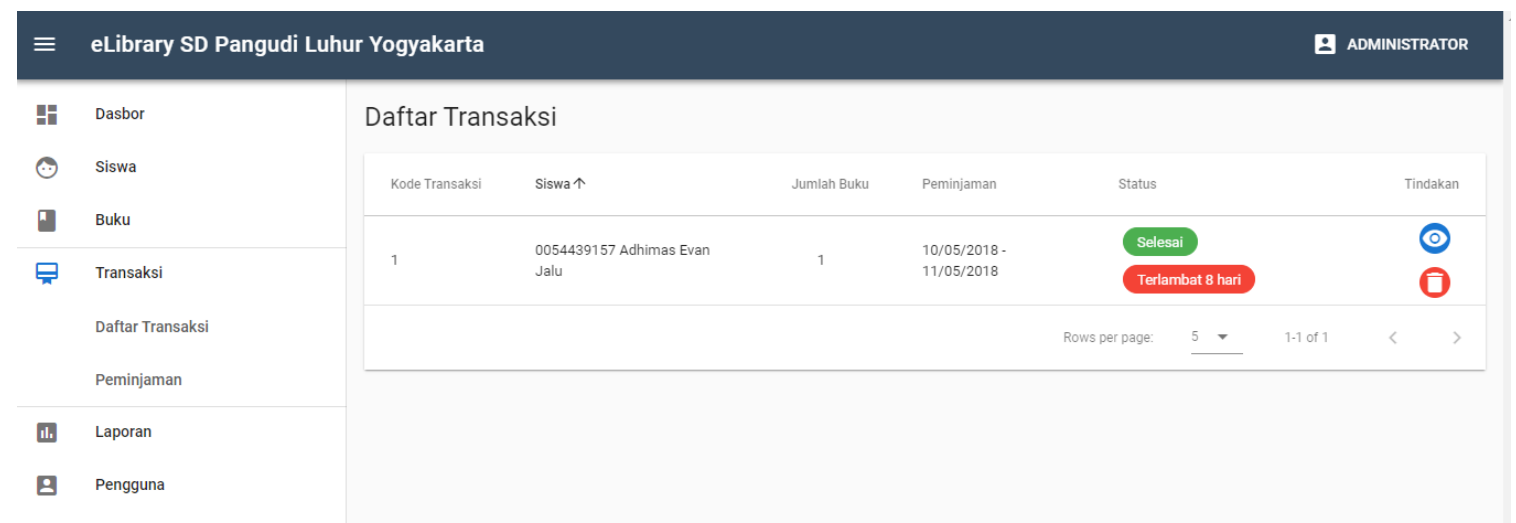

Gambar 8 Antarmuka Daftar Transaksi Peminjaman

Antarmuka pada Gambar 9 merupakan menu untuk melakukan transaksi peminjaman buku dengan memasukkan ISBN atau judul buku yang akan dipinjam. Kemudian mengisikan nama siswa dan tanggal berapa buku dipinjam dan akan dikembalikan. Nama siswa dapat diisikan dengan melakukan scan barcode pada kartu peminjaman siswa. Untuk mencatat pengembalian buku, tanggal kembalinya diperbaharui menjadi tanggal ketika buku dikembalikan.

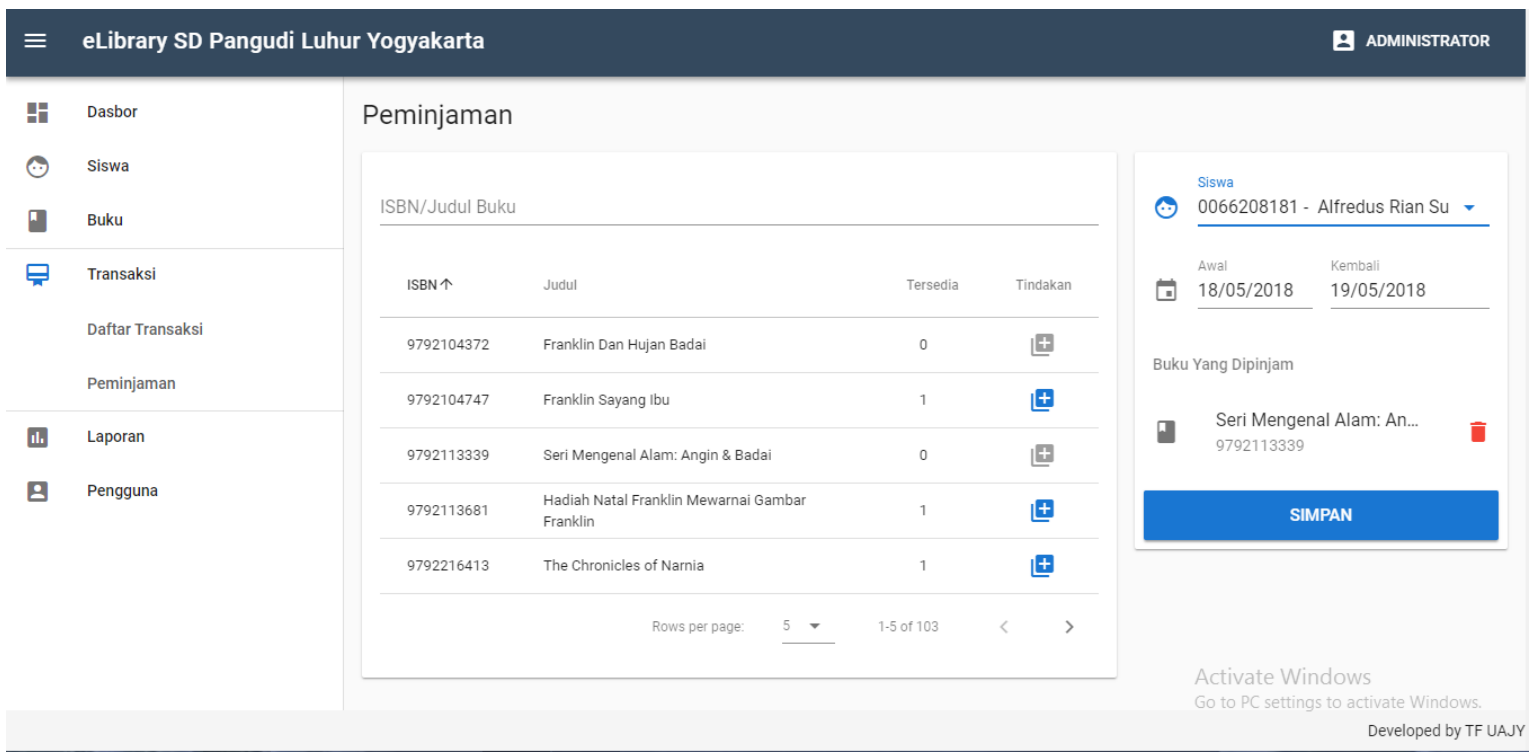

Gambar 9 Antarmuka Transaksi Peminjaman dan Pengembalian

Menu laporan mempunyai dua sub menu yaitu laporan peminjaman dan laporan buku rusak. Pada Gambar 10 merupakan antarmuka yang berisi tampilan laporan buku yang sedang dipinjam yang dapat di-filter berdasarkan bulan dan tahun peminjaman. Pada Gambar 11 merupakan antarmuka yang berisi tampilan laporan data buku yang rusak. Laporan ini menampilkan ISBN, judul buku, kategori dan jumlahnya untuk memudahkan dalam menemukan buku yang rusak tersebut. 


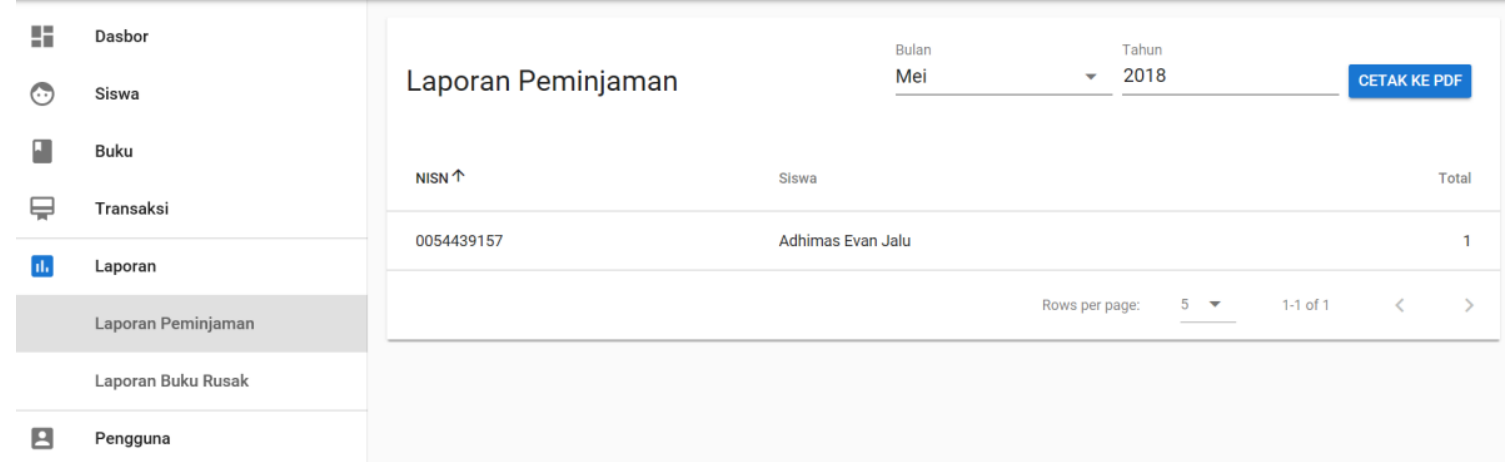

Gambar 10 Antarmuka Laporan Peminjaman

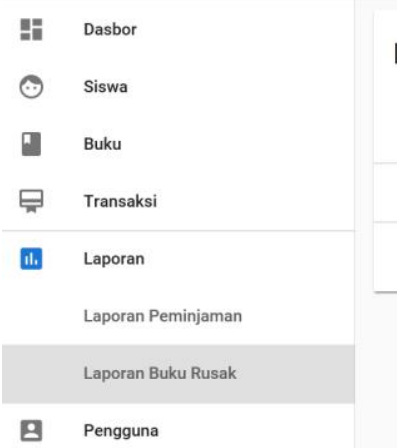

Laporan Buku Rusak

Gambar 11 Antarmuka Laporan Buku Rusak

Dapat dilihat dari beberapa penjelasan mengenai sistem yang dibangun, proses administrasi konvensional dari perpustakaan SD Pangudi Luhur Yogyakarta berhasil diubah menjadi proses komputerisasi. Sistem informasi perpustakaan berbasis web telah berhasil dilakukan deployment pada server, sehingga bisa diakses melalui alamat https://elibrarysdpljogja.org. Hal ini sangat membantu pengelola perpustakaan di SD Pangudi Luhur Yogyakarta untuk melayani siswa siswi dengan lebih efektif dan efisien. Permasalahan yang muncul ketika proses dijalankan secara konvensional pun dapat diatasi. Sebagai contoh dengan penggunaan sistem ini, data-data seperti data buku dan siswa dapat tercatat dengan rapi. Risiko kehilangan data menjadi sangat minim karena seluruh data tersimpan di server. Keuntungan yang lain adalah proses yang menjadi lebih efektif. Karena sistem ini dibangun berbasis web maka selama komputer terkoneksi dengan jaringan internet maka proses pelayanan di perpustakaan SD Pangudi Luhur Yogyakarta tidak tergantung oleh satu orang saja. Beberapa orang yang diberikan akses ke sistem dapat membantu proses pelayanan peminjaman buku ke siswa siswi agar menjadi lebih cepat. Hal lain yang dapat dirasakan dengan penggunaan sistem ini adalah proses stok opname buku yang menjadi lebih cepat dan valid. Sistem telah menyediakan laporan buku yang dipinjam dan buku rusak. Pengelola perpustakaan hanya tinggal mencocokkan ketersediaan buku dengan laporan tersebut. Proses yang awalnya membutuhkan waktu yang lama kini menjadi lebih singkat.

Beberapa keuntungan yang dijelaskan tersebut merupakan umpan balik yang diberikan oleh pengelola perpustakaan. Sistem ini sudah berhasil diimplementasikan serta dilakukan pelatihan seperti dapat dilihat pada Gambar 12 dan Gambar 13. Mereka sangat puas dan sangat terbantu dengan adanya sistem ini. Dari pihak sekolah pun mengharapkan tidak hanya administrasi perpustakaan yang menerapkan teknologi informasi tetapi jika memungkinkan administrasi kesiswaan sampai ke media pembelajaran pun dapat ditunjang dengan teknologi informasi. 


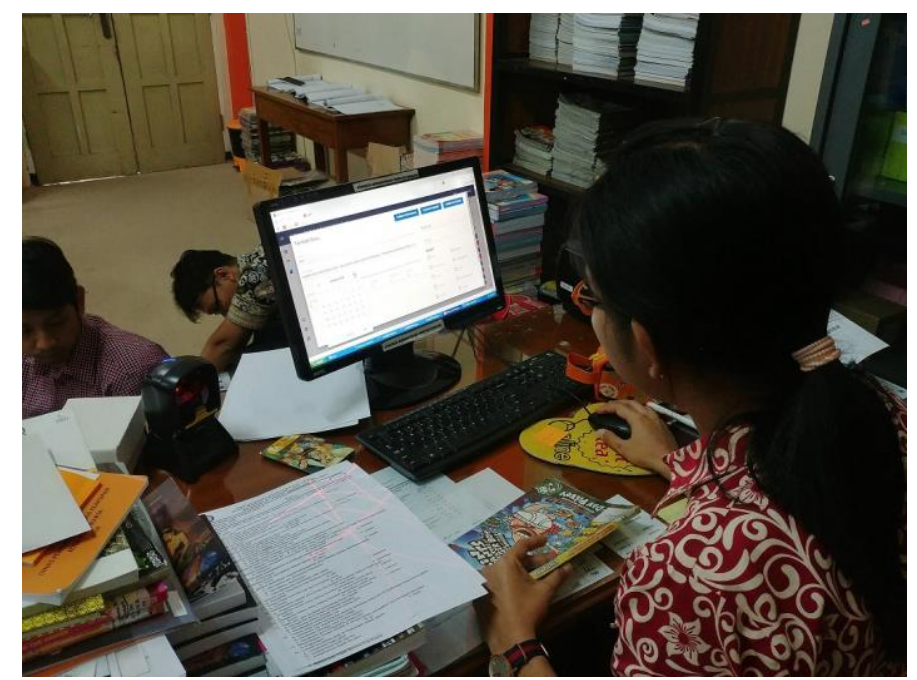

Gambar 12 Pelatihan Sistem Informasi Perpustakaan

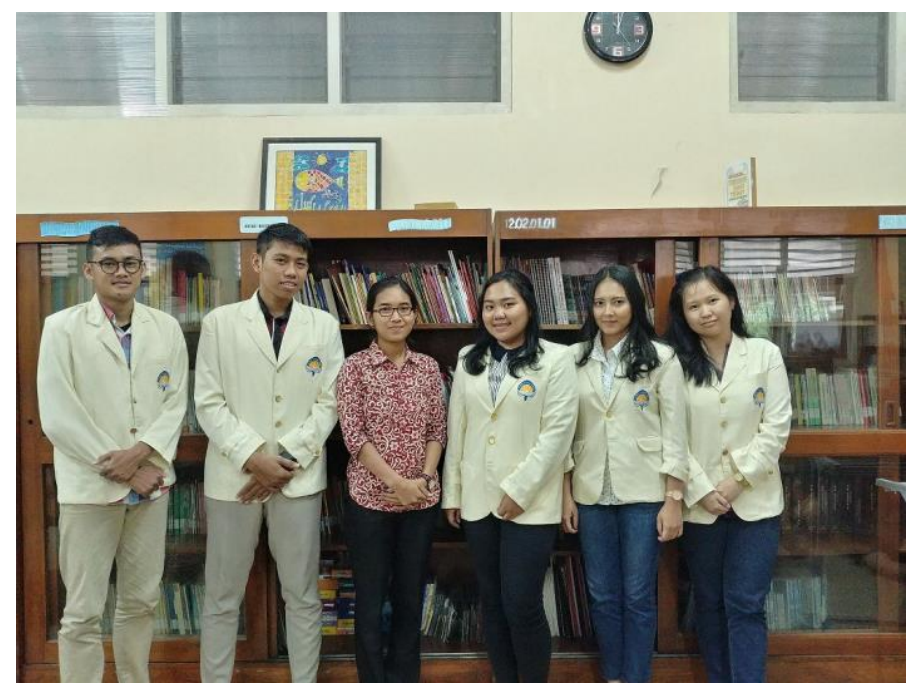

Gambar 13 Tim Pelatihan Bersama dengan Pengelola Perpustakaan

\section{KESIMPULAN}

Pengabdian berupa pembangunan sistem perpustakaan berbasis web untuk perpustakaan SD Pangudi Luhur Yogyakarta telah berhasil dilaksanakan. Pelatihan kepada pengelola perpustakaan juga sudah direalisasikan guna memberikan pengalaman penggunaan sistem informasi perpustakaan yang matang. Keluaran yang dihasilkan adalah sebuah sistem informasi perpustakaan berbasis web yang bertujuan untuk mempermudah proses peminjaman buku di perpustakaan SD Pangudi Luhur Yogyakarta. Hasil yang didapatkan dari pihak sekolah sangat positif mengingat sistem ini sangat membantu proses bisnis pada perpustakaan.

\section{SARAN}

Pengembangan yang perlu ditambahkan untuk menyempurnakan sistem informasi perpustakaan berbasis web ini adalah notifikasi untuk memberikan peringatan kepada peminjam bahwa buku yang dipinjam sudah mendekati tanggal pengembalian atau sudah terlambat.

\section{DAFTAR PUSTAKA}

[1] F. Aziz, and M.M.S Akhtar, "Impact of training on teachers competencies at higher education level in Pakistan," Researchers World, vol. 5, no. 1, pp. 121, 2014. 
[2] M. Taufiq, "Pengaruh Teknologi Informasi Dalam Keprofesian Dan Implikasinya dalam Dunia Pendidikan," Naturalistic: Jurnal Kajian Penelitian Pendidikan dan Pembelajaran, vol. 1, no. 2, pp. 176-185, 2017.

[3] S. N. Arif, A.P. Wanda, and A. Masudi, "Aplikasi Administrasi Perpustakaan Berbasis Web SMK Swasta Brigjend Katamso Medan," Jurnal SAINTIKOM, Vol. 12, no. 1, pp. 25-36, 2013.

[4] H. S. Ensour, and T. M. Alinizi, "THE IMPACT OF MANAGEMENT INFORMATION SYSTEMS (MIS) TECHNOLOGIES ON THE QUALITY OF SERVICES PROVIDED AT THE UNIVERSITY OF TABUK," International Journal of Network Security \& Its Applications, vol. 6, no. 2, pp. 1, 2014.

[5] F. Hariadi, "Pembuatan sistem informasi perpustakaan pada SDN Sukoharjo pacitan berbasis web," IJNS-Indonesian Journal on Networking and Security, vol. 2, no. 4, 2012.

[6] Saliman, "Sistem Informasi Berbasis Komputer (CIBS)," EFISIENSI-Kajian Ilmu Administrasi, vol. 7, no. 12007.

[7] I. Yuadi, "Perpustakaan Digital: Paradigma, Konsep, dan Teknologi Informasi yang digunakan," Jurnal Jurusan Ilmu Informasi dan Perpustakaan FISIP Unair Surabaya, pp. 28-35, 2007.

[8] Ermatita, "Sistem Informasi Perpustakaan SMP Santo Louis Palembang," Jurnal Informatika, vol. 16, no. 1, pp. 43-50, 2016.

[9] M. Yusri, "Sistem Informasi Perpustakaan Berbasis Web pada SMP Frater Makassar," JUPITER, vol. 14, no. 2, pp. 66-77, 2015.

[10] U. M. Sari, and D. Djuniharto, "Sistem Informasi Perpustakaan Di SMK Gajah Mada Banyuwangi," Konferensi Nasional Sistem Informasi (KNSI), pp. 442-448, 2018.

[11] A. R. Kasmirin, M. Yusman, and I. Adipribadi, "PERANCANGAN SISTEM INFORMASI PERPUSTAKAAN BERBASIS WEB (Studi Kasius SMAN 1 Penengahan)," Jurnal Komputasi, vol. 4, no. 1, pp. 104-108, 2016.

[12] R. Hardi, and H. Hardianto, "Pengembangan Sistem Informasi Perpustakaan Menggunakan Kerangka Pieces (Studi Kasus Perpustakaan STITEK Bontang)," Jurnal Ilmiah Teknologi Informasi Terapan, vol. 1, no. 3, pp. 15-21, 2016. 